Canadian Journal of Family and Youth, 13(2), 2021, pp. 82-94

ISSN 1718-9748@ University of Alberta

http://ejournals, library, ualberta.ca/index/php/cjfy

\title{
Developing Students' Creative Constructs in Mathematics with Problem-Based (PB) and Problem Posing (PP) Tasks
}

\begin{abstract}
The purpose of this experimental study was to examine the creative constructs of students enrolled in Differential Calculus at the University of Science and Technology of Southern Philippines, Cagayan de Oro City, Philippines. This study was composed of 132 engineering and mathematics education students enrolled in two different semesters. The experimental group was chosen randomly, exposed to the problem-based HALP model teaching approach and problem posing while the control group was taught using Polya's problem-solving heuristics. Multiple Solution Tasks (MST) test in Calculus was administered to determine their creative constructs which can be measured in terms of their level of mathematical fluency, flexibility and novelty of solutions before and after the experiment. Results indicated that the experimental group exhibited a remarkable improvement of their mathematical fluency and flexibility but still in the developing level when they are required to posit novel solutions to problems as influenced by the problem-based HALP and problem posing activities. Hence, it is recommended that mathematics teachers may utilize these methods to successfully develop students' mathematical creativity and future research may also be explored on integrating technology and how it can influence developing student's mathematical creativeness as well as the mediating role of their affective domains and IQ (intelligent quotient).
\end{abstract}

Keywords: problem-based Hawaii Algebra Learning Project (HALP), problem posing, Polya's problem solving heuristics, creativity, fluency, flexibility, novelty

Dr. Dennis B. Roble is an Associate Professor II of the Department of Mathematics Education of the College of Science and Technology Education (CSTE) of the University of Science and Technology of Southern Philippines (USTP), Cagayan de Oro City. Dr. Roble graduated both his Doctor of Philosophy in Mathematical Sciences major in Mathematics Education as a CHED Dissertation Grantee Scholar under the K-12 Transition Program. Before he joined USTP, he was a Secondary Mathematics Teacher at Balulang National High School, Department of Education (DepEd) in the Division of Cagayan de Oro City 
from 2011 to 2015. Dr. Roble was recently awarded as a Research Productivity Awardee of the USTP System. Recent publications include: Roble, D.B. and Janneth Q., Rondina. (2019). "Game-based Design Mathematics Activities and Students' Learning Gains". The Turkish Online Journal of Design, Art and Communication (TOJDAC), Volume 9, Issue 1, pp. 1-7; Roble, D.B. and Maria Antonieta A. Bacabac. (2016). "Teaching Proficiency and Preparedness of Pre-service Mathematics Teachers: Its Implications to Actual Practice". American Journal of Education Research, Vol 4, No. 15; Roble, D. B. (2016). The Geometer's Sketchpad: A Technological Tool Enhancing Junior High School Students' Mathematics Achievement, Attitude towards Mathematics and Technology. American Journal of Educational Research, 4(15), 1116-1119 and Roble, D.B. and Charita A. Luna. (2017). "Strengths of Formative Assessments (Daily Time-pressured Quiz, Homework and Portfolio) on Students' Summative Assessment Performance in Integral Calculus" Liceo Journal of Higher Education Research (LJHER), Volume 13 No.1.

Laila S. Lomibao is a Full Professor and currently the Dean of the College of Science and Technology Education of the University of Science and Technology of Southern Philippines, Cagayan de Oro City. Dr Lomibao graduated her PhD in Mathematical Sciences major in Mathematics Education at USTP. Also, before she joined the USTP System, she has also served as a secondary school teacher of the Department of Education (DepEd), division of Cagayan de Oro City. Dr. Lomibao was also recently awarded as Research Productivity Awardee of the USTP System. Her recent publications include: Cajandig, A. J. S., \& Lomibao, L. S. (2020). 5I's Learning Path with Cultural Approach Embedded to CAI on Student's Conceptual Understanding. American Journal of Educational Research, 8(10), 772-778; Bacabac, M. A. A., \& Lomibao, L. S. (2020). 4S Learning Cycle on Students' Mathematics Comprehension. American Journal of Educational Research, 8(3), 182-186; Maandig, R. B., Lomibao, L. S., \& Luna, C. A. (2017). Structured Content Reading Instruction vs. Direct Instruction: Their Implication on Students' Achievement, Reading Comprehension and Critical Thinking in Mathematics. American Journal of Educational Research, 5(5), 574-578; Lomibao, L. S., Luna, C. A., \& Namoco, R. A. (2016). The influence of mathematical communication on students' mathematics performance and anxiety. American Journal of Educational Research, 4(5), 378-382; Lomibao, L. S. (2016). Enhancing mathematics teachers' quality through Lesson Study. SpringerPlus, 5(1), 1-13.

Charita A. Luna is a Professor Emeritus and a Graduate School Faculty of the College of Science and Technology Education of the University of Science and Technology of Southern Philippines, Cagayan de Oro City. Her recent publications include: Ticar, M. A. J., Luna, C. A., \& Tan, R. G. (2020). Argumentative Discourse-centered Classroom to Hone Students' Mathematical Comprehension and Confidence. American Journal of Educational Research, 8(5), 304-308; Luna, C. A., Rondina, J. Q., \& Dazo, N. V. (2020). Varied Intervention Models: It's Effect on Students' Retention Score. American Journal of Educational Research, 8(5), 321-324; Coronado, W. A., Luna, C. A., \& Tarepe, D. A. (2017). Improving Students van Hiele and Proof-writing ability using Geometer's sketchpad. Journal of Social Sciences (COES\&RJ-JSS), 6(2Special), 55-74; Maandig, R. B., Lomibao, L. S., \& Luna, C. A. (2017). Structured Content Reading Instruction vs. Direct Instruction: Their Implication on Students' Achievement, Reading Comprehension and Critical Thinking in Mathematics. American Journal of Educational Research, 5(5), 574-578 and Lomibao, L. S., Luna, C. A., \& Namoco, R. A. (2016). The influence of mathematical communication on students' mathematics performance and anxiety. American Journal of Educational Research, 4(5), 378-382. 


\section{Contribution to the Literature/Paper Originality}

- This paper is the product of a two (2) semester experiment at the University of Science and Technology of Southern Philippines. The nature of the study being experimental was already distinct to other studies which can be found in the literature where most of the exploration was purely qualitative. In this study, a pre-test and post-test was given to determine the extent of influence of the teaching approach on students' creative constructs.

- Moreover, in this study, the researchers used a work text in Differential Calculus where students can answer problems directly after the lesson where the problem-based Hawaii Algebra Learning Project (HALP) model and pre-within-post problem posing was integrated in the lesson and the student activities.

- The Multiple Solution Tasks (MST) test was inspired by the work of Leiken (2009) but the questionnaire developed was originally made by the researcher since it only focuses on Differential Calculus competencies and was validated in the pilot study.

\section{Introduction}

Philosophers summed up the emerging present world system in four principles which are universalism, globalism, interdependence and creativity, while other contemporary scholars viewed creativity as the "cultural capital of the $21^{\text {st }}$ century" for it is among the most important and pervasive of all human ability (Sheridan-Rabideau, 2010). Creativity requires experimentation, formulation of new hypotheses, and open possibilities. Britten (2012) attributed economic success to innovative thinking and he stated that creativity reduces inequalities and improves the quality of living. Hence, creativity is one of the fundamental requirements to survive in this present generation.

Contemporary schools need to prepare students to work in current workplaces and teachers must help students to develop these skills needed for success. Among the most important $21^{\text {st }}$ century skills which may help students adapt to the changing society, is to develop their creativity and intellectual curiosity. Creativity is an integral part of mathematics. It is traditionally supposed to attribute to art and literature, but recently doing meaningful science has also been considered as a creative act. In a mathematics classroom, students who are creative seem to possess the quality of good problem solvers with excellent critical thinking skills which the present society needs.

In relation to the teaching and learning of mathematical concepts, students need to possess creative thinking and problem-solving skills and as such, mathematics educators must also design activities that promote creativity among students. Creative learners are those students who can easily think in many ways to find alternatives to answer problems in mathematics. Considering the importance of creativity, the role of mathematics educators is to design activities that can foster the development of students' mathematical creativity. Mathematical creativity was first explored by Poincare and Hadamard at the beginning of the $20^{\text {th }}$ century (Sriraman, 2009). Nevertheless, 
this concept was not discussed in detail until recent years (Leikin, Pitta-Pantanzi, 2013). In fact the National Council of Teachers of Mathematics (NCTM) Standards for Mathematics Education did not list creativity explicitly as one of the main strands. However, the elements listed in the NCTM and the Common Core State Standards (CCSS) of the United States focal points are considered by many researchers as one of the fundamental components of creativity.

Problem solving and problem posing methods are believed to be an indispensable part of educating students in mathematics. The problem-based Hawaii Algebra Learning Project (HALP) model is a problem solving approach which requires students to solve assignment problems before classroom discussion proved to be an effective method in enhancing students' achievement in mathematics (Swain, 2004). The present study employed this problem-solving approach because students were tasked to discover the answer to the problem before discussion, which this present study theorized would help to develop students' mathematical creativity while Polya's four-step problem solving heuristics strategy are rules of thumb in successful problem solving (Schoenfeld, 2014). However, Polya considered problem solving in a mathematics class impoverished without enriching it with problem posing, hence, the present study integrated both activities. Problem posing is considered to be a vector for learning (Singer, Ellerton \& Cai, 2013). In context to the present study, the researchers utilized a pre-within-post problem posing activities because the researchers believed that the tandem of problem-based and problem posing activities could develop students' mathematical creativity at an optimal level.

In order to evaluate students' level of mathematical creativity in terms of their mathematical fluency, flexibility and originality/novelty of solutions, the Multiple Solution Tasks (MST) test proposed by Kantorovich, Koichu, Leikin and Berman (2011) was followed but in this study, selected topics in Differential Calculus was carefully decided and made to ensure that minimum competencies of the course was successfully met. In this test, students are tasked to answer the problems in the MST test in many different ways aimed to measure the mentioned categories of creativity and explained further if they can only posit one solution for the problem.

In view of the above, this present study investigated the development of the creative constructs of students as influenced by a teacher's use of the problem-based Hawaii Algebra Learning Project (HALP) model and problem posing activities integrated in the lesson activities as well as in the work text in Differential Calculus which the researchers developed as the main instructional material used in this study. This work test underwent a pilot study in the previous semester and the content was validated by mathematics education experts and passed the instructional materials (IM) committee of the university, that is, the work text is fit for distribution among students.

\section{Methodology}

This study utilized a mixed method of research which includes a quantitative quasiexperimental control group and a qualitative design. The quantitative part of this study examined the effect of integrating problem-based HALP model activities in the work text in Differential Calculus. The extent of the significant difference of the performance of both the experimental and control groups was tested using the Pretest-Posttest Control Group Design. This study was con- 
ducted at the University of Science and Technology of Southern Philippines (USTP). USTP is a state university established on August 16, 2016 by virtue of Republic Act 10919 through the amalgamation of the Mindanao University of Science and Technology (MUST) in Cagayan de Oro City, Misamis Oriental and the Misamis Oriental State College of Agriculture and Technology (MOSCAT) in Claveria, Misamis Oriental. Both campuses are located in Northern Mindanao, the Gateway to Mindanao, which offers a strategic location advantage for the institution to train and develop students from all the other regions of Mindanao. The participants of this study were two (2) sections of engineering students in Differential Calculus enrolled in the second semester of the 2016-2017 school year and the other were BSEd majors in mathematics in the first semester of the 2017-18 school year. The students in the second semester were 57 engineering students and the first semester was 75 mathematics education students. The instrument used in this study was the teacher-made Multiple Solutions Tasks (MST) tests which are all open-ended problems in Differential Calculus and after item analysis; only four questions were left and obtained a 0.74 reliability coefficient. The work text in Differential Calculus was piloted and validated using another Calculus class offered in the first semester of SY 2016-2017. The performance of the students in the achievement test and Multiple Solutions Tasks (MST) test was described using statistical tools such as mean and standard deviation.

Before the treatment started, both the experimental and control groups were given a pretest on the open-ended MST test in Differential Calculus. The participants were all handled by the researcher to minimize the effect of the teacher factor as an intervening variable that may affect the results of this study. Furthermore, the students were not informed that they were the participants of the study to avoid the Hawthorne effect. There were three class observers assigned to both groups to avoid bias and were asked to answer the observers' evaluation questionnaire. Of the three class observers, two (2) are faculty of the Department of Mathematics Education while the other one is the student teacher assigned for the researcher during the conduct of the experiment. The experimental group was exposed to the problem-based HALP model activities integrated in the Differential Calculus work text which requires them to do mathematical tasks such as providing different solutions in a given problem. The creative task used varies depending on the type of problems. Before the treatment, students were grouped randomly with the assumption that these students in groups possessed different learning styles and academic performance. The treatment group was required to read the work text to equip them with the concepts of derivatives and given homework problems solving tasks and they worked collaboratively with homework problem on the concepts and applications of derivatives. Every member of the group has responsibilities. Students were supposed to participate actively in the group discussion. They had to share their knowledge, express their ideas and experiences with each other while searching a solution for the problem. Apart from the group work, each student had to conduct an independent study and must be able to represent, communicate and evaluate his or her learning at both individual and group levels. During the session, the teacher organized the groups to create a purposeful and cooperative atmosphere. The teacher ensured that students had control of the discussion. Whenever guidance was needed, the teacher asked open-ended, very general questions and gave ample opportunity to students to focus on the goal. The teacher encour- 
aged students to create new solutions. After the activities, students were tasked to answer the exercises in the work text in Differential Calculus where they were required to provide many alternative solutions most especially those which are novel or unfamiliar.

In the control group, students used Polya's steps in problem solving activities with similar topics that are found in the work text in Differential Calculus. Students were required to write with description of each step as follows: (1) understanding the problem; (2) make a plan; (3) carry out the plan; and (4) evaluate the solutions. In the first step, the students were asked what the problem is all about, what is given and not given, and what they need to find. Secondly, in making the plan, they were asked what strategies they need to choose and use such as looking for a pattern, making a table, working backwards and any other method. In carrying out the plan, students performed the necessary algorithms, described the steps done, and evaluated the solution. When all the topics or tasks were completed, both groups were given a post-test of the MST test to determine if there was an improvement in their scores.

\section{Results and Discussion}

The following table presents the level of mathematical fluency, flexibility, and novelty of solutions as indicators of students' creative constructs in Calculus. Table 1 shows the level of students' mathematical fluency of both the experimental and control groups from the two different semesters when the study was conducted.

Table 1: Students' Level of Mathematical Fluency in Calculus

\begin{tabular}{|c|c|c|c|c|c|c|c|c|c|}
\hline \multirow{2}{*}{\multicolumn{2}{|c|}{ Participants }} & \multicolumn{4}{|c|}{ Experimental Group $(n=75)$} & \multicolumn{4}{|c|}{ Control Group $(n=57)$} \\
\hline & & $\bar{x}$ & sd & $\bar{y}$ & sd & $\bar{x}$ & sd & $\bar{y}$ & sd \\
\hline \multicolumn{2}{|c|}{ Mathematics Education } & 8.05 & 3.08 & 15.00 & 1.69 & 8.63 & 3.74 & 13.31 & 2.66 \\
\hline \multicolumn{2}{|c|}{ Engineering } & 3.64 & 3.07 & 9.88 & 2.93 & 4.20 & 3.14 & 8.40 & 1.84 \\
\hline \multicolumn{2}{|c|}{ Overall } & 5.85 & 3.08 & 12.44 & 2.31 & 6.41 & 3.44 & 10.86 & 2.25 \\
\hline Legend: & $\begin{array}{l}\text { Mean Intervals } \\
15.50-16.00 \\
12.5-15.49 \\
8.50-12.49 \\
4.50-8.49 \\
1.00-4.49\end{array}$ & & $\begin{array}{l}\text { Descri| } \\
\text { Excelle } \\
\text { Profici } \\
\text { Approa } \\
\text { Develo } \\
\text { Beginn }\end{array}$ & ng Proficic & & $\begin{array}{l}\bar{x} \\
\bar{y} \\
\mathrm{sd}\end{array}$ & $\begin{array}{l}\text { Pretest } \\
\text { Posttest } \\
\text { Standard }\end{array}$ & Score is 16 & \\
\hline
\end{tabular}

Results reveal that first experimental group obtained a mean score of 8.05 which indicates a developing level in their mathematical fluency. The first control group showed an approaching proficiency level in their mathematical fluency while the experimental and control groups of the second set of participants showed a beginning level of their mathematical fluency. Overall, both the experimental and control groups exhibited a developing level of mathematical fluency which 
indicates that all groups already had a background in the topics in Differential Calculus. This might be due to the fact that the other group enrolled in this subject twice and their experience with the subject helped them answer the questions correctly.

In the post-test, both the experimental and control groups showed an improvement in their mathematical fluency scores as indicated by the increase of their post-test scores. The experimental group and control group of the first set of participants obtained mean scores of 15.00 and 13.31, respectively, which have a descriptive level of proficient. However, the experimental group showed a greater increase of 6.95 as compared to the control group which only get 4.68 increase in their post-test scores. The experimental and control groups of the second set of participants showed also an improvement of their post-test scores. The experimental group had a bigger increase as compared to the control group but still on the approaching proficiency descriptive level. The control group showed an increase but still on the developing level. The increase of their scores might be due to the fact that they experienced problem solving and problem posing activities integrated in the work text in Differential Calculus during class sessions.

Taken altogether, before the start of the experiment, both the experimental and control groups obtained scores which are described as a developing level with the control group gaining a score difference of 0.57 as compared to the experimental group. This result indicates that before the experiment started, both groups were still developing their mathematical fluency as evidenced by their scores in the pre-test. In the post-test, both groups gained an increase of their fluency scores which reaches the approaching proficiency level. However, in this case, the experimental group obtain a higher score compared to the control group which indicates that the students' exposure to the work text with problem-based and problem solving activities helped them improved their fluency scores. Although, the experimental group showed larger increase of their fluency scores, the control group also showed an increase which might be influenced by their exposure to problem posing activities and Polya's problem solving strategies. Sample solutions of students in the experimental and control groups are shown below:

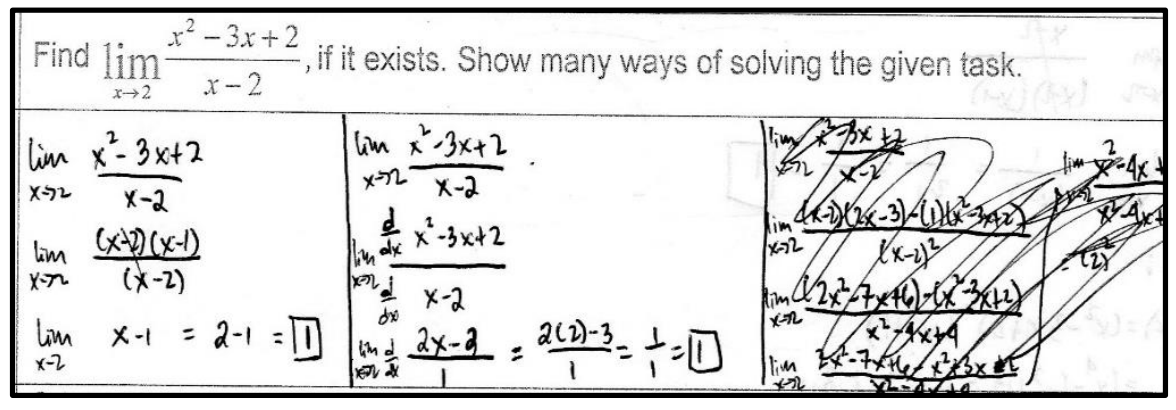

Figure 2: Student Ma3V1F2Exp1 Answer for Multiple Solution Tasks (MST) Test Item \# 1 on Finding Limits of a Function

It can be seen in the above solution of the student in the experimental group that she was able to show two (2) different solutions in finding the limit of the function. Student Ma3V1F2Exp1 was able to apply factoring in finding the limit in order to get rid of an indeterminate solution and 
also, it is surprising to note that she was able to apply L'Hospital's rule in finding limits, that is, she computed the derivatives of both the numerator and denominator. Her solutions suggest that she has an advanced knowledge in Differential Calculus because this topic was not discussed in class. Also, the student attempted to find the limit by applying quotient rule in computing the derivative of the rational function, however, she erased her answer realizing that it would give her a different value of the limit. This indicates that the student did some reflections in her solutions which is an indicator of critical thinking skill considering the alternative solutions giving the same answer as expected. Another solution of the student who belonged to the control group is shown below:

$$
\begin{aligned}
& \text { PROBLEM } \\
& \text { Find the derivative of } f(x)=\left(x^{2}-3 x+2\right)^{2}\left(x^{3}+1\right) \text { in different methods. } \\
& \begin{aligned}
f(x) & =\left(x^{2}-3 x+2\right)^{2}\left(x^{3}+1\right) \\
& =\left(x^{4}-6 x^{3}+13 x^{2}-12 x+4\right)\left(x^{3}+1\right) \\
f^{\prime}(x) & =\left(x^{4}-6 x^{3}+13 x^{2}-12 x+4\right)\left(3 x^{2}\right)+\left(x^{3}+1\right)\left(4 x^{3}-18 x^{2}+26 x-12\right) \\
& =3 x^{6}-18 x^{5}+39 x^{4}-36 x^{3}+12 x^{2}+4 x^{6}-18 x^{5}+26 x^{4}-12 x^{3}+4 x^{3}-18 x^{2}+26 x-12 \\
f(x) & =7 x^{6}-36 x^{5}+65 x^{4}-44 x^{3}-6 x^{2}+26 x-12
\end{aligned}
\end{aligned}
$$

Figure 3: Student EnggSC1F1C1 Answer to the Multiple Solutions Tasks (MST) Test Item \# 3 on Computing the Derivative Applying Chain Rule

The female engineering student of the control group answered the problem on finding the derivative of the polynomial function using different methods. The problem presented can be solved efficiently using product rule and chain rule directly. However, the student opted to expand first the trinomial and then use the product rule. The reason might be that the student would find chain rule more complex than expanding the trinomial. This indicates that the student was not able to master the concept of the chain rule and divert to solutions which she can manage to execute. The solution might be very practical in a sense that the student was able to master the expansion of the trinomial however; she might not be mathematically flexible for she has only provided one solution for the problem. This implies that the Calculus teacher needs to explain clearly how the chain rule can be applied especially when dealing with problems like these where students tend to look for solutions which they think would be very easy to execute. This is good but the concept of chain rule was not illustrated and would translate that the student has not exhibited mathematical fluency in this topic. 
Table 2: Students' Level of Mathematical Flexibility in Calculus

\begin{tabular}{ccccccccc}
\hline Participants & \multicolumn{3}{c}{ Experimental Group $(n=75)$} & \multicolumn{4}{c}{ Control Group $(n=57)$} \\
\cline { 2 - 9 } & $\bar{x}$ & $\mathrm{sd}$ & $\bar{y}$ & $\mathrm{sd}$ & $\bar{x}$ & $\mathrm{sd}$ & $\bar{y}$ & $\mathrm{sd}$ \\
\hline Mathematics Education & 5.81 & 1.70 & 9.06 & 1.37 & 5.88 & 1.78 & 7.91 & 1.08 \\
\hline Engineering & 3.49 & 2.40 & 8.83 & 2.32 & 3.80 & 2.68 & 8.36 & 2.61 \\
\hline Overall & $\mathbf{4 . 6 5}$ & $\mathbf{2 . 0 5}$ & $\mathbf{8 . 9 5}$ & $\mathbf{1 . 8 5}$ & $\mathbf{4 . 8 4}$ & $\mathbf{2 . 2 3}$ & $\mathbf{8 . 1 4}$ & $\mathbf{1 . 8 4}$ \\
\hline
\end{tabular}

Table 2 above shows the level of students' mathematical flexibility during the pre-test and post-test. It can be observed from the Table that during the pre-test, the regular mathematics education group of participants obtains mathematical flexibility scores which are in the developing level while the special class of engineering students are still in the beginning level as indicated by their pre-test scores. Taken altogether, the experimental and control groups of this study showed a developing level of mathematical flexibility before the start of the experiment. This result suggests that students in both groups have partial understanding of the concepts in Calculus.

In the post-test, both experimental groups showed an increase in their flexibility scores which reaches an approaching proficiency level of mathematical flexibility. The first experimental group showed a better increase as compared to the second experimental group and this goes to show that exposure to the Calculus work text with problem-based HALP model and problem posing activities helped the students improve their mathematical flexibility especially that in the exercise students were tasked to solve problems in many different ways.

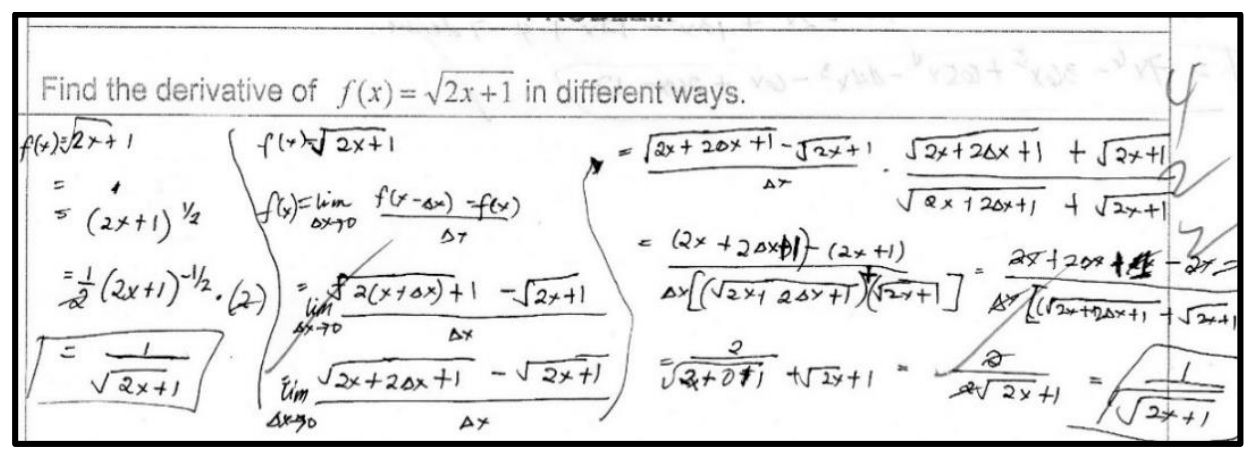

\section{Figure 4: Student Ma3V1M2Exp1 Answer to the Multiple Solutions Tasks (MST) Test Item \# 2 on Computing the Derivative Applying Chain Rule}

The figure shows the solution of the student on finding the derivative of the radical function which can be solved using chain rule. Student Ma3V1M2Exp1 was able to show two different solutions. In the first solution, the student was able to apply chain rule efficiently and in the second 
solution, he was able to apply the limit definition of derivative. The student's answers suggest that he exhibited flexibility in presenting two different solutions for the problem. Although the solution was quite familiar as it was discussed earlier before chain rule, the student managed to recall the concept of the derivative using the limit definition. This implies that the student retained previous topics and was able to recall that the problem can be solved using the limit definition of the derivative. The control group, however, only showed a developing level after the experiment but at least they have improved their flexibility as shown in their scores during the post-test. However, the majority of them were able to execute only the chain rule process in getting the derivative of the same item as mentioned above and for the rest of the items in the Multiple Solutions Tasks (MST) test.

Taken jointly, the same result showed that the experimental groups reached the approaching proficiency level and the control groups only reach the developing level in terms of their mathematical flexibility scores in the post-test. This indicates that both groups improved but the experimental group showed higher increase as compared to the control groups which means that the problem-based HALP and problem posing activities helped the students improved their mathematical flexibility scores. The control group also showed an increase because they are also exposed to problem solving and problem posing activities. Below is a solution of one of the students in the control group.

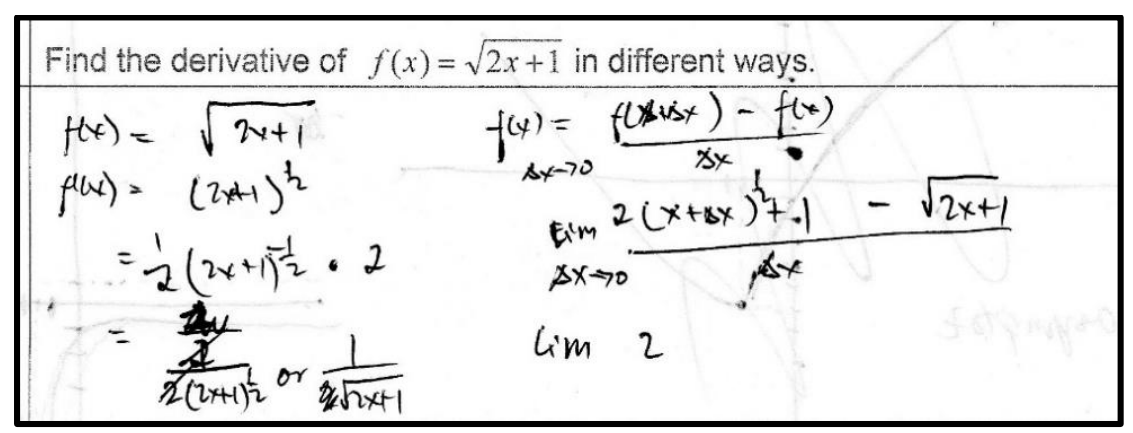

\section{Figure 4: Student EnggSC1F2C2 Answer to the Multiple Solutions Tasks (MST) Test Item \# 2 on Computing the Derivative Applying Chain Rule}

Student EnggSC1F2C2 was able to apply chain rule in the problem and attempted to apply the limit definition of the derivative, however, the student did not continue the solution. This indicates the students in the control group showed a developing level of mathematical flexibility which can be enhanced if they are exposed to the activities done in the experimental groups.

Table 3: Students' Level Mathematical Novelty of Solutions in Calculus

\begin{tabular}{ccccccccc}
\hline Participants & \multicolumn{3}{c}{ Experimental Group $(n=75)$} & \multicolumn{4}{c}{ Control Group $(n=57)$} \\
\cline { 2 - 9 } & $\bar{x}$ & $\mathrm{sd}$ & $\bar{y}$ & $\mathrm{sd}$ & $\bar{x}$ & $\mathrm{sd}$ & $\bar{y}$ & $\mathrm{sd}$ \\
\hline Mathematics Education & 4.18 & 1.37 & 8.45 & 1.39 & 4.39 & 1.61 & 7.74 & 0.99 \\
\hline Engineering & 3.85 & 2.69 & 7.53 & 3.83 & 3.76 & 2.57 & 6.73 & 3.81 \\
\hline Overall & $\mathbf{4 . 0 2}$ & $\mathbf{2 . 0 3}$ & $\mathbf{8 . 0 2}$ & $\mathbf{2 . 6 1}$ & $\mathbf{4 . 0 8}$ & $\mathbf{2 . 0 9}$ & $\mathbf{7 . 2 4}$ & $\mathbf{1 . 2 8}$ \\
\hline
\end{tabular}


Table 3 above shows students' level of originality or novelty of their solutions for the Calculus problems in the Multiple Solutions Tasks (MST) test before and after the experiment. Results reveal that both the experimental and control groups of all sets of participants of this study were at the beginning level of originality of their solutions as presented in the MST test. This result suggests that all of the participants still need to develop their skills in creating novel solutions for mathematical problems.

During the post-test, both groups improved however they only reached the developing level which indicates that the students were not able to attain proficiency in terms of providing novel solutions for problems. These students were able to provide solutions which are familiar, that is, those that were able to encounter during the course. One solution of a student from the experimental group is shown below:

\begin{tabular}{|c|c|c|c|c|}
\hline \multicolumn{5}{|c|}{ Find $\lim _{x \rightarrow 2} \frac{x^{2}-3 x+2}{x-2}$, if it exists. Show many ways of solving the given task. } \\
\hline $\lim _{x \rightarrow 2} \frac{x^{2}-3 x+2}{x-2}$ & $x$ & $\lim _{x \rightarrow 2} \frac{x^{2}-7 x+2}{x-2}=1$ & $x \mid$ & $\lim _{x \rightarrow 2} \frac{x^{2}-3 x+2}{x-2}=1$ \\
\hline $\begin{array}{l}\lim _{x \rightarrow 2} \frac{(x-1)(x-2)}{x-2} \\
\lim _{x \rightarrow 2} \\
=2-1=1\end{array}$ & $\begin{array}{l}1.9 \\
1.99 \\
1.949 \\
1.994 \\
1.49999 \\
1.999494\end{array}$ & $\begin{array}{l}69 \\
019 \\
0.199 \\
0.9999 \\
0.99999 \\
0.919999\end{array}$ & $\begin{array}{l}2.4 \\
2.0001 \\
0.0001 \\
2.001 \\
2.01 \\
2.1\end{array}$ & $\begin{array}{l}1.00001 \\
1.0001 \\
1.001 \\
1.01 \\
1.1\end{array}$ \\
\hline
\end{tabular}

Figure 5. Student Ma3V1M2Exp1 Answer to the Multiple Solutions Tasks (MST) Test Item \# 2 on Computing the Limit of the Function Applying Factoring Method

In the solution above of student Ma3V1M2Exp1, he was able to compute the limit using factoring but as an alternative, he was able to investigate the trend of the value of the function from the left and right of 2 . This indicates that the student understood the concept of limit, that is, by showing the equality of left-hand and right-hand limits. This is the only student among all groups who was able to show this kind of solution, which can be considered original while the majority of other participants showed familiar solutions. This indicates that the experimental group was able to develop their originality of solutions because in the work text they are tasked to provide novel solutions. However, the control groups also showed a developing level of originality which means that the problem-solving and problem posing activities helped them develop their level of providing novel solutions to problems in the MST test.

\section{Concluding Statements}

Based on the results, it can be concluded that problem-based HALP model integrated in the work text in Differential Calculus is more effective than Polya's problem solving heuristics in 
improving students' creative constructs in terms of mathematical fluency and flexibility but showed only a little improvement for providing novel solutions to the problems in Calculus. This scenario was expected as Leikin, Levav-Waynerg \& Guberman (2011) as they concluded that the development of mathematical creativity, the triad dimension of fluency-flexibility-originality, fluency and flexibility are of dynamic in nature while originality is a gift. This paper then suggests that there is a need to improve teachers' pedagogy which provides an educational atmosphere where students struggle productively such as problem-based HALP model activities and problem posing activities. Hence, it is recommended that mathematics teachers try out these methods to successfully develop students' mathematical creativity. Future research may also be explored on integrating technology and how it is influential in developing students' mathematical creativeness as well as the mediating role of their affective domains and IQ (intelligent quotient). 


\section{References}

Britten, S. (2012). Can creativity fix South Africa? Mail \& Guardian Online. Accessed from https://mg.co.za/article/2012-03-26-can-creativity-fix-south-africa/.

Kontorovich, I., Koichu, B., Leikin, R., and Berman, A. (2011). "Indicators of creativity in mathematical problem posing: How indicative are they?" In M. Avotina, D. Bonka, H. Meissner, L. Sheffield, and E. Velikova (Eds.), Proceedings of the 6th International Conference Creativity in Mathematics Education and the Education of Gifted Students Latvia: Latvia University, (pp. 120-125).

Leikin, R., Levav-Waynberg, A., \& Guberman, R. (2011). Employing multiple solution tasks for the development of mathematical creativity: Two comparative studies. In Proceedings of the Seventh Conference of the European Research in Mathematics Education (pp. 1094 1103).

Leikin, R. \& Pitta-Pantazi, D. (2013). "Creativity and mathematics education: the state of the art". ZDM, 45, 159-166.

Schoenfeld, A. H. (2014). Mathematical problem solving. London, United Kingdom: Academic Press Ltd.

Sheridan-Rabideau, M. (2010). “Creativity repositioned”. Arts Education Policy Review, 111, 54 58. doi:10.1080/10632910903455876.

Singer, F. M., Ellerton, N., \& Cai, J. (2013). "Problem-posing research in mathematics education: New questions and directions". Educational Studies in Mathematics, 83(1), $1-7$.

Sriraman, B. (2009). "The characteristics of mathematical creativity". Zentralblatt für Didaktik der Mathematik, 41(1-2), 13-27.

Swain, J. S. (2004). An evaluation of Hawaii Algebra Learning Project (HALP) and Polya's Problem Solving Model in Selected Word Problems. Master's Thesis, Mindanao Polytechnic State College, Cagayan de Oro City, Philippines. 